\title{
RAZGLEDI
}

\section{LEDINSKA IMENA NA KULTURNIH TERASAH}

AVTOR

\section{dr. Matjaž Geršič}

Znanstvenoraziskovalni center Slovenske akademije znanosti in umetnosti, Geografski inštitut Antona Melika, Gosposka ulica 13, SI - 1000 Ljubljana, Slovenija

matjaz.gersic@zrc-sazu.si

DOI: $10.3986 / G V 88205$

UKD: 911.53:631.613: 81'373.21(497.4)

COBISS: 1.01

\section{IZVLEČEK}

\section{Ledinska imena na kulturnih terasah}

$V$ članku predstavljamo analizo ledinskih imen na terasiranih območjih izbranih katastrskih občin $v$ jugozahodni Sloveniji. Ledinska imena smo na vnaprej zamejenih terasiranih območjih identificirali v različnih virih in jih s pomočjo postopka georeferenciranja $v$ geografskih informacijskih sistemih umestili v enoten koordinatni sistem. Z etimološkimi slovarji smo pri izbranih imenih skušali najti povezavo $z$ rabo tal in drugimi lastnostmi poimenovane ledine.

\section{KLJUČNE BESEDE:}

geografija, imenoslovje, zemljepisno ime, toponim, ledinsko ime, kulturna terasa, Slovenija

\section{ABSTRACT}

\section{Field names in agricultural terraces}

The article analyses field names in agricultural terraces of selected cadastral municipalities in south-west Slovenia. Field names for previously delimited agricultural terraces were identified in different sources and placed into a uniform coordinate system by means of georeferencing. Etymological dictionaries were then used to help determine a connection with land use and other features of the land unit in question.

\section{KEY WORDS}

geography, onomastics, geographical name, toponym, field name, agricultural terraces, Slovenia

Uredništvo je prispevek prejelo 20. julija 2016. 


\section{Uvod}

Poimenovanje živih in neživih stvari je ena od najstarejših dejavnosti v vseh kulturah. Zato ne preseneča, da so ljudje že zelo zgodaj poimenovali tudi različne geografske značilnosti prostora. Najprej so posamezniki poimenovali območja v neposredni okolici bivališč, kamor so hodili na lov in so bila povezana $\mathrm{z}$ vsakodnevnim življenjem, posebno še z gospodarstvom (Kadmon 2000, 4). S poimenovanjem namreč nek prostor dobi pomen in identiteto znotraj družbene skupnosti (Penko Seidl 2011). Okolje, v katerem ni imen, deluje kaotično, onemogoča orientacijo in lahko zato deluje strašljivo (Relph 1977, 17).

Ko človek prostor poimenuje, mu pripiše določen pomen in ga na nek način udomači (Penko Seidl 2011). Imena namreč niso nič drugega, kot skrajšani opisi (Cathcart in Klein 2008, 138). Da ima ime nek pomen oziroma je simbol (nosilec globlje vsebine) poimenovanega objekta, lahko povzamemo tudi iz latinskega pregovora »Nomen est omen « (»Ime je znak«) Johanna Jacoba Eglija iz druge polovice 19. stoletja (Kadmon 2000, 37).

Zemljepisna imena poimenujejo objekte na površju Zemlje (Kadmon, Radovan in Majdič 1995, 16) in spadajo med lastna imena (Furlan, Gložančev in Šivic-Dular 2001, 14). Lastnost lastnih imen je, da nedvoumno identificirajo in individualizirajo poimenovani objekt. Funkcijsko gledano so lastna imena namenjena natančni identifikaciji imenovanega objekta $\mathrm{v}$ smislu njegove vrstnosti in tudi individualizaciji v smislu konkretnega objekta (entitete). Pri pregledu fonda zemljepisnih imen ugotovimo, da se lahko enako ime uporablja za imenovanje več entitet v okviru iste vrste topografskega objekta na različnih koncih jezikovnega ozemlja. V onomizaciji so takšna imena nastajala neodvisno eno od drugega (Furlan, Gložančev in Šivic-Dular 2001, 14).

Zemljepisna imena delimo na naselbinska in nenaselbinska. Naselbinska nadalje delimo na imena naselij oziroma mest, vasi in zaselkov, nenaselbinska pa na petintrideset različnih kategorij; ena izmed njih so ledinska imena oziroma imena ledin (Furlan, Gložančev in Šivic-Dular 2001, 24-25).

$\mathrm{V}$ pričujočem članku smo se osredinili na ledinska imena izbranih terasiranih območij v jugozahodni Sloveniji in skušali ugotoviti, ali se v njih zrcali kakšna značilnost kulturnih teras.

\section{Metode}

Prva faza pri raziskovanju zemljepisnih imen je njihovo zbiranje. Poteka lahko na terenu, kjer s pomočjo domačinov zbiramo in zapisujemo različne tipe imen na v naprej pripravljene zemljevide ali v preglednice. Druga možnost je zbiranje imen iz že obstoječih virov, bodisi kartografskih bodisi drugih pisnih virov. Najboljši vpogled v aktualno stanje in rabo zemljepisnih imen krajevnega značaja dobimo s kombinacijo obeh metod.

Med viri zemljepisnih imen so neprecenljivi zgodovinski katastri. Ti nam omogočajo identifikacijo imen, iz primerjave s sodobnim stanjem pa lahko ugotovimo, katera imena so se izgubila, katera so se spremenila, nastala na novo in podobno. Slabost zgodovinskih katastrov je njihova neumeščenost v koordinatni sistem in otežena primerjava lokacije posameznih imen s sodobnim stanjem. Pri tem si pomagamo z geografskimi informacijskimi sistemi, kjer lahko s pomočjo prekrivanja različnih kartografskih slojev zgodovinske katastre georeferenciramo in tako določimo lokacijo posameznih imen na sodobnih zemljevidih.

Pri motivacijski razlagi ledinskih imen so nepogrešljiv vir raziskovanja etimološki slovarji in razpoložljiva literatura s sorodno tematiko.

\section{Nastanek ledin in ledinskih imen}

Človek je s svojim delovanjem v pokrajini na podlagi naravnih dejavnikov ustvaril kulturno pokrajino. Glavni preoblikovalec je bilo kmetijstvo. Zaradi različne primernosti tal za obdelavo je bil vaški prostor s poljsko razdelitvijo razdeljen na več delov, poimenovanih z lastnimi imeni (Penko 2013). 
Ledine so bile prvotno zaključene površine, ki so imele isti gospodarski pomen (Jarc 2004, 254). Nastale so kot posledica spremembe rodovno plemenske družbene ureditve pri Slovanih. Po opustitvi selilnega kmetijstva in ko lov, ribolov in nabiralništvo niso več zadoščali za prehransko oskrbo, so ljudje udomačili prve rastlinojede živali ter jih zadrževali v ogradah, kjer so se pasle. Te ograde so imenovali stanovi (Fabčič 2010, 14). Drug način nastanka ledin je bila kolonizacija nenaseljenih območij. Naseljenci so del površja iztrebili in zemljišče razdelili na večja polja, ledine. Spremembe v obdelavi njiv, predvsem kolobarjenje in gnojenje, so povzročile, da se je nekdaj skupna (srenjska) zemlja dokončno razdelila. Najprej je ta proces dosegel njivska zemljišča, pozneje travnike, na koncu pa še gozd. V skupni lasti so ostali le še pašniki (Jarc 2004, 254). Večje ledine so se delile na manjše tudi zaradi različnih družbenih procesov, kot so prodaja, dedovanje, razlaščanje zemljišč, pri čemer so posamezni deli lahko dobili svoja imena.

Beseda ledina izvira iz indoevropske besedne baze *lendh-, kar pomeni "prosta, neobdelana zemlja«. Besede iz te baze v drugih evropskih jezikih pomenijo tudi »izkrčeno mesto v gozdu «, »strnišče«, "praha«, »stepa«, »ozemlje«, »zemlja«, »pusta pokrajina«, »dolina« (Snoj 1997, 296).

Ledinska imena, po definiciji imena manjšega nenaseljenega kraja (Snoj 2009, 16), praviloma označujejo temeljne značilnosti in lastnosti vaškega zemljišča (Kladnik 1999, 62). Razdelitev vaškega prostora na ledinske enote izhaja iz trajnih kolektivnih predstav o naravni delitvi prostora. Meje med posameznimi ledinami pogosto potekajo po naravnih ločnicah, kot so vznožja, vrhovi in grebeni, rečne struge. Tako so v ledinskih imenih izražene temeljne značilnosti naravnega prostora in vsi človekovi posegi, nastali v želji, da bi se te lastnosti izboljšale (Penko 2013). Večino ledin so poimenovali domačini, nekatere pa so poimenovali tudi geometri, ki so delali izmere za posamezne katastre (Ribnikar 1982, 329 v: Fabčič 2010, 14). Nekatera ledinska imena pa niso nič drugega kot splošni geografski pojmi, prilagojeni določeni geografski posebnosti (na primer naravni nesreči; Geršič in Zorn 2016), kjer iz zapisa izhaja, da gre za lastno ime (Fabčič 2012). Sodobni procesi spreminjanja podeželja povzročajo, da znotraj posamezne ledine zemljiška kategorija ni več enotna. Ledina je tako izgubila svoj prvotni pomen, je pa v zavesti domačinov še vedno prisotna kot celota, čeprav lahko v sodobnosti na določeni ledini opazimo različno rabo tal.

Čeprav nekatera ledinska imena danes nič več ne izražajo lastnosti, po katerih so bila poimenovana, so vendarle ostala nespremenjena (Penko 2013).

\section{Viri ledinskih imen ter metode njihovega zbiranja in zapisovanja}

Ledinska imena kot kartografski element so prvič sistematično zapisana na zemljevidih franciscejskega katastra (Kladnik 1999, 62), pred tem pa so se ohranjala le v ustnem izročilu (Fabčič 2010, 25). Franciscejski kataster sestavljajo zemljevidi in protokoli. Protokoli vsebujejo različne opise ter podatke o stavbah, parcelah in podobnem, vsebujejo pa tudi ledinska imena (Ribnikar 1982, 330-331 v: Fabčič 2010, 25). Franciscejski kataster je bil dokončan leta 1828, leta 1869 pa so izdelali reabmbulančni kataster, ki pa za vse nekdanje avstrijske dežele ni v celoti ohranjen (medmrežje 1). Tudi reambulančni kataster vsebuje ledinska imena, zato je tam, kjer je na razpolago, pomemben vir, na podlagi katerega lahko opazujemo spremembe ledinskih imen v času med izdajama obeh katastrov. Tretji zgodovinski vir ledinskih imen so posestni listi posameznih katastrskih občin, nastali konec 19. in na začetku 20. stoletja. Posestni listi so sestavljeni podobno kot franciscejski kataster, imena pa so zapisana v slovenskem jeziku (Fabčič 2010, 27).

Sodoben vir ledinskih imen je Register zemljepisnih imen Republike Slovenije (REZI) v merilu 1:5000. Gre za uradno evidenco in vsebuje imena objektov, ki so stalni in imajo neko časovno, zgodovinsko, etnološko ali družbeno uveljavljeno identiteto (Pogorelčnik 1999, 107; Peršolja 2003, 112). Izredno pomemben vir, predvsem kadar ugotavljamo aktualno rabo ledinskih imen in njihovo narečno različico, pa so domačini, informatorji. Najboljši informatorji so starejši ljudje, ki poznajo domače življenjsko 
okolje in način življenja. Navadno so najboljši informatorji kmetje, gozdni delavci, lovci, ribiči (Klinar s sodelavci 2012, 19).

Poseben izziv pri zbiranju ledinskih imen je njihovo zapisovanje. Jezika zapisov v franciscejskem katastru sta nemški ali italijanski, v reambulančni različici pa je zapis slovenski. Tudi zapis v REZI-ju je slovenski, težava pa nastane pri informatorjih, ki pri govoru uporabljajo domače narečje.

Zapis ledinskih imen prilagodimo namenu raziskave; uporabljamo lahko znanstveni dialektološki zapis, poenostavljen narečni zapis ali poknjižen zapis (Klinar s sodelavci 2012, 39).

Pri prostorski zamejitvi raziskovanega območja imamo različne možnosti. Zaradi možnosti primerjave sodobnih in zgodovinskih virov se je kot najprimernejša prostorska enota izkazala katastrska občina. Meje katastrskih občin se večinoma niso spreminjale in so od časov izdelave franciscejskega katastra ostale približno enake. Druge enote so lahko naselja, župnije, občine, krajevne skupnosti; vendar so te meje praviloma bolj spremenljive od meja katastrskih občin.

\section{Dosedanje raziskave ledinskih imen}

Ledinska imena so rezultat razvoja pokrajine in jezika (Fabčič 2010,11). Pri njihovem preučevanju se stikajo in prepletajo raziskovalni interesi jezikoslovcev (jezik), geografov in krajinskih arhitektov (prostor) ter zgodovinarjev (razvoj, časovna komponenta). Poleg omenjenih se z ledinskimi imeni ukvarjajo tudi etnologi.

Ledinska imena na slovenskem ozemlju so predmet obravnave več kot 25 diplomskih in raziskovalnih nalog. Precej posameznikov se z zbiranjem in obravnavo ledinskih imen ukvarja ljubiteljsko, nekateri med njimi so izdelali kakovostne raziskave, na primer Jarc (2004) in Silič (2012). Med bolj sistematične raziskave ledinskih imen spada delo Klinarja s sodelavci na območju Gorenjske (na primer Klinar in Geršič 2014), kot predmet doktorske disertacije je ledinska imena na Gorenjskem obravnaval Čop (1983), na Goriškem pa Šekli (2006). Med monografskimi publikacijami, ki kot osrednjo tematiko obravnavajo ledinska imena, omenimo deli Julija Titla Toponimi Koprskega primorja in njegovega zaledja (Titl 2000) in Kraški toponimi (Titl 2006) ter delo z naslovom Pripoved izročila talov (Fabčič 2010). Med znanstvenimi članki je vredno izpostaviti članka Pomen toponimov s poudarkom na ledinskih imenih $z a$ proučevanje kulturne krajine (Penko Seidl 2008) in Ledinska imena v prostoru in času (Penko Seidl 2011). Poleg omenjenih so ledinska imena obravnavana $\mathrm{v}$ številnih člankih, objavljenih $\mathrm{v}$ različnih strokovnih in poljudnih revijah, pogosto pa tudi v raznih krajevnih zbornikih.

\section{Ledinska imena kot del kulturne dediščine}

Zaradi dolgotrajne rabe lahko ledinska imena izgubijo svoj nekdanji stvarni pomen, predmetno ali besedotvorno prepoznavnost. Če jo ohranjajo, so nosilec sporočila o stanju in rabi pokrajine v času njihovega nastanka in zanesljiv spremljevalec procesa preoblikovanja pokrajine od prvobitne naravne do današnje kulturne pokrajine (Peršolja 2002, 364). Ohranjena zemljepisna imena, s katerimi so bili poimenovani polja, travniki, njive, gozdovi, rovti, lazi, poti, vode, deli vasi, deli vzpetin in planine, so zgodovinski in kulturni spomeniki in kot taka zato pomemben del nacionalne kulturne dediščine, hkrati pa bogata jezikovna dediščina, ki je v času naglega spreminjanja življenja ogrožena bolj kot kadarkoli doslej (Kunaver 1988, 125; Silič 2012, 54). O kulturni vrednosti ledinskih imen daje slutiti tudi njihova uvrstitev na UNESCO-v seznam nesnovne kulturne dediščine v sosednji Avstriji (Piko-Rustia 2010, 15). Leta 2010 jih je skupaj s hišnimi imeni Nacionalna agencija za nesnovno kulturno dediščino Avstrije (Nationalagentur für das Immaterielle Kulturerbe in Österreich) sprejela med pomembno avstrijsko nesnovno kulturno dediščino. Nesnovna dediščina je opredeljena kot prvina, ki pripomore k ohranjanju kulturne raznolikosti in trajnostnega razvoja v regiji (Klinar s sodelavci 2012, 9). Čeprav so ledinska imena omejena na 
določeno krajevno skupnost, znotraj katere se je izoblikoval kolektivni spomin, jih je zaradi njihove dediščinske vrednosti treba nujno ohranjati tudi v pisni obliki. Zapis spominov je namreč edino sredstvo njihove rešitve (Halbwachs 2001, 55-95 v: Fabčič 2010, 21). Možnosti za zapis ledinskih imen je več. Med najpogostejšimi oblikami so zemljevidi, najbolje v kombinaciji z besedilom, kjer so ledinska imena dodatno pojasnjena. Mogoča je tudi spletna različica takšnih zemljevidov, kjer lahko posameznemu ledinskemu imenu dodamo posnetek izgovora v narečju, dodatne fotografije in podobno.

\section{Rezultati in razprava}

Katastrske občine v katerih smo obravnavali ledinska imena (slika 1), so med seboj zelo različne. $Z$ vidika imenoslovnih raziskav izpostavimo predvsem različno razpoložljivost virov in njihovo neusklajenost. Franciscejski kataster je na voljo za vse obravnavane katastrske občine, vendar je pri občini Šmartno v Goriških brdih število ledinskih imen zelo skromno. Večinoma so vpisana le nekdanja krajevna imena, ki so danes večinoma ovrednotena kot ledinska. Reambulančni kataster je na razpolago le za naselji Krkavče in Šmartno, pri čemer v Šmartnem ledinskih imen skorajda ni. Za ostale katastrske občine reambulančni kataster bodisi ni bil narejen bodisi je izgubljen ali uničen. Za analizo ledinskih imen lahko torej uporabimo franciscejski kataster kot zgodovinski vir in register zemljepisnih imen kot sodoben vir ledinskih imen. Imena, identificirana $v$ katastrih, so zapisana v ležeči pisavi, imena iz REZI-ja pa v običajni. Če smo določeno ime identificirali v obeh katastrih, je na prvem mestu zapisano starejše ime.

V katastrski občini Ostrožno Brdo smo identificirali okrog dvajset sklenjenih terasiranih območij. Vsako ni poimenovano z ledinskim imenom, nekaj primerov pa je takšnih, da eno terasirano območje pokriva več imen. V nekaterih primerih je očitno, da je ime vezano izključno na terasirano območje, drugod so terase le del poimenovane ledine. Primeri imen, vezanih izključno na terase, so Cehalov hrib (Za Per Luje), Dula (Dula), Ravne njive (Raune Nive), Gradnje, Cerkune, Megovenci, Brda (Turnoberdo), Zalotke, Močilni breg (Moccilo Brech), Mrzli devci in na Sojah. Večji terasirani območji v severozahodnem delu vasi sta v franciscejskem katastru poimenovani s štirimi imeni: Doline, Traunoberdo, Spelane Nive in Douge Nive, REZI pa jih navaja pet: Travno brdo, Škrnije, Špelanke, pri Brezju in Pleši.

V katastrski občini Podgorje sta le dve večji sklenjeni terasirani območji. Severovzhodno od glavne vaške ceste je ledina Ravan (Pod Losech Rovan), za jugovzhodni del te ledine pa REZI navaja še ime Podboršt. Drugo večje terasirano območje je jugozahodno od vaškega središča. Zanj franciscejski kataster navaja imena Horizeste Ograde, Pod Ograde, Rouble na Gorizah, Per Shiroke pole, Pod Stran, Per Krisha in Pod Vraze, reambulančni pa pod Ogrado, Brajde, Sodelna, Janjčje Barede, Kavčja Dolina in v Dužci.

V katastrski občini Kamnje je nekaj manj kot dvajset terasiranih območij. Tako franciscejski kataster kot tudi REZI vsebujeta zelo skromno število ledinskih imen. Imeni, ki pripadata terasiranemu območju, sta Brajde (Braida) in Treschnik.

Katastrska občina Krkavče je izrazito terasirana, saj lahko naštejemo preko dvajset zaključenih območij s terasami, med razpoložljivimi viri pa je tudi reambula franciscejskega katastra. Med ledinskimi imeni, ki pripadajo posameznemu zamejenemu območju teras, naj omenimo imena Nebelice (Cortivo Bene, Maccugtiac), Mačkujek (Mascujac, Maccugliac), Patrinka, Ukovca (Ugrada, Ugrada), Glavinska korita (Missiza, Missiza), med takšnimi, kjer je na posameznem terasiranem območju več ledinskih imen, pa Žvabi (Suabi, Suabi), Gradišče, Dovac, Hrib (Crib, Crip), Velika njiva, Verenike (Moscalo, Moscalo).

Katastrska občina Merče je glede ledinskih imen podobna Kamnju. Število ledinskih imen je zelo skromno, kar velja tako za kataster kot REZI. Tudi število sklenjenih območij s terasami ni veliko, so le štiri. Edino ime iz franciscejskega katastra, ki večinoma pripada območju teras, je Nad Praida. REZI ledinskih imen terasiranih območij v tej katastrski občini ne vsebuje.

Slika 1: Obravnavane katastrske občine. str. 96 


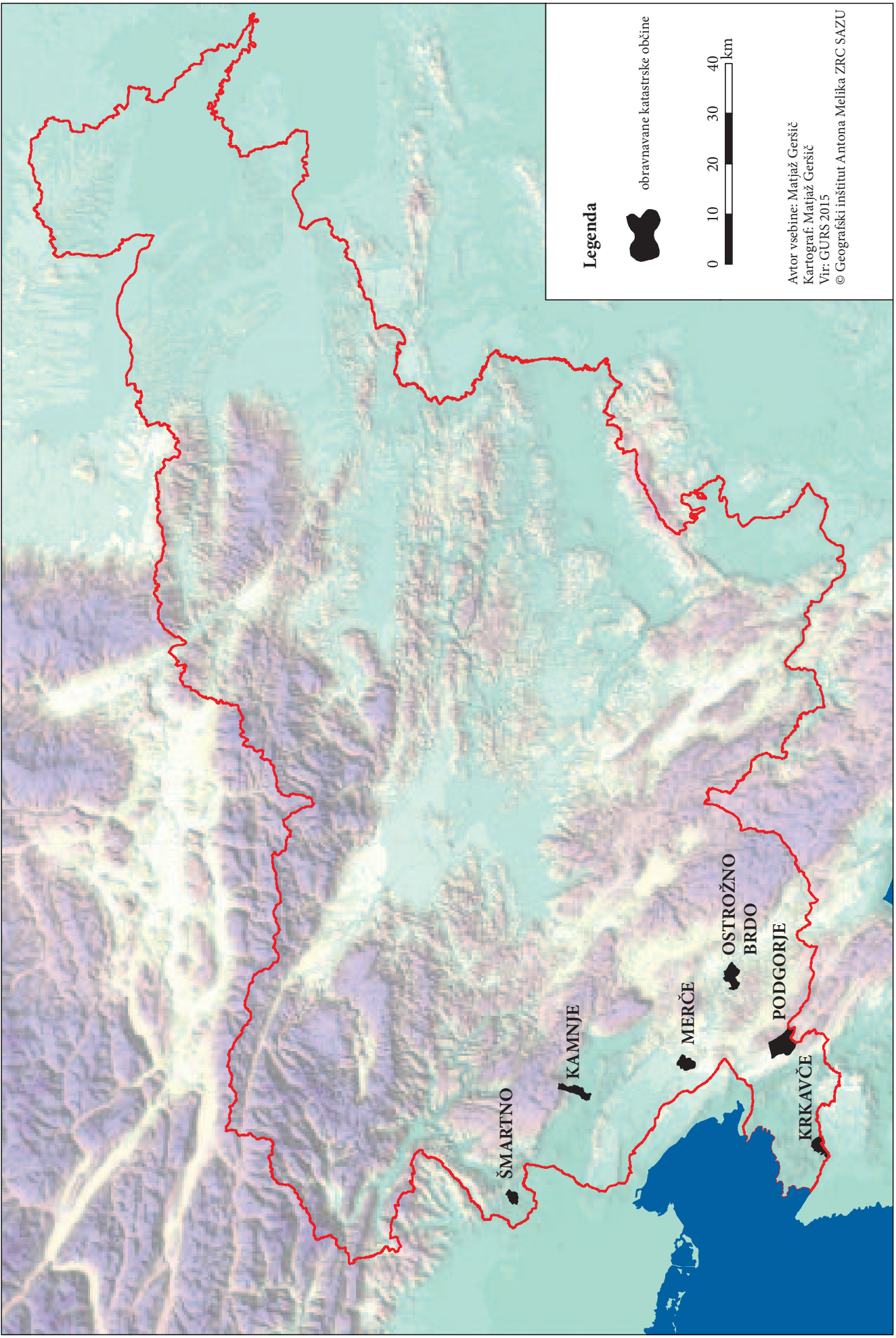


Katastrska občina Šmartno v Goriških brdih je po številu sklenjenih terasiranih območij gotovo največja, $v$ franciscejskem katastru pa terasiranemu območju pripada eno samo ime. To je Imegna, ki je enako tudi v reambuli katastra. Bistveno več imen je v REZI-ju. Ledinska imena, ki pripadajo terasiranim območjem, so Veliko, Zabrdce, Dolina, Drage, Poljce, Polje, Ravnice, Kovačevca, Bukovce, Mlake, Zdenec, Slinavci, Vidnica, Na Pušči, Perilo, Pašnja, Pirovi, Ronk, Bale, Gonjače, Bratnja, Gornji konec, Dolnji konec, Polje, Imenje, Konica, Teja, Gospoblaževi, Konjedic, Dolina, Polje, V koncu, Močilo, Gonjače, Lazno, Planjca in Zapihavc. Ker je večina terasiranih območij razmeroma velikih, jim pripada po več ledinskih imen. Primera, ko je posamezno ime očitno poimenovalo zelo omejeno terasirano območje, sta le Dolina in Lazno.

Če ledino definiramo, kot navaja Jarc (2004), da gre za sklenjena zemljišča, ki so imela isti gospodarski pomen, lahko ugotovimo, da pri terasiranih območjih zelo redko naletimo na primere, kjer bi eno samo ledinsko ime pokrivalo določeno zamejeno območje kulturnih teras. Ledinska imena večinoma označujejo širša območja, katerih določeni deli so terasirani, ali pa ima določeno terasirano območje več ledinskih imen. Med primeri, kjer ledinsko ime lepo sovpada z zamejenim terasiranim območjem, lahko izpostavimo ime Ravne njive (Raune Nive) na Ostrožnem Brdu (slika 2).

S tem imenom navadno imenujemo najboljši del njivskih zemljišč v kraju. Značilno je, da so posamezne njive ena od druge ločene po omejkih, njivskih brežinah ali terasah in potekajo vzdolž izohips (Ilešič 1950, 64-65). Ledinska imena teras, vezana na samostalnik njiva ali polje, se pojavljajo še v katastrskih občinah Krkavče (Velika njiva), Šmartno (Poljce, Polje), Podgorje (Per Shiroke pole) in Ostrožno Brdo (Šeplanke, Spelane Nive).

Drug primer na Ostrožnem Brdu, kjer tako sodobno kot zgodovinsko ime sovpadata s terasiranim območjem, je Močilni breg (franciscejski kataster navaja Moccilo Brech). Beseda močilo izhaja iz staroslovenske besede močidlo in pomeni vodni vir (Badjura 1953, 231). Iz imena tako lahko sklepamo, da na vznožju brega izvira potok, kar je vidno tudi na zemljevidih franciscejskega katastra. V tem primeru konkretne povezave med ledinskim imenom in kulturnimi terasami ni.

Da so terase nastale na nekdanjih pobočjih oziroma so del pobočij, pričajo številna imena, povezana s samostalniki breg, hrib in podobno, na primer Brda (Turnoberdo, Traunoberdo) na Ostrožnem Brdu, Rouble na Gorizah v Podgorju in Hrib (Hrip, Hrip) v Krkavčah.

Zanimivo ledinsko ime, ki ga v sodobnosti težko povezujemo s terasiranim območjem je izpeljano iz samostalnika dolina. Takšni primeri na Ostrožnem Brdu so Doline, Dula (Dula), v Podgorju Kavčja dolina, v Krkavčah Dovac, v Šmartnem pa Dolina in Drage.

Dolina je v geografski terminologiji opredeljena kot »...podolgovata, vsaj na eni strani odprta globel..." (Kladnik, Lovrenčak in Orožen Adamič 2005, 77), kar seveda nima neposredne povezave z ledinskim imenom Dolina. V preteklosti so namreč mnoge ravninske dele (pasove ali ploskve) označevali na različne načine, med drugim z občnimi imeni, kakršno je na primer dolina (Badjura 1953, 31).

Nekoliko nejasno je ledinsko ime Lazna. Badjura trdi, da ga ne pozna, pojem laz pa enači s pojmom raven (Badjura 1953, 44), medtem ko Snoj $(1997,249)$ domneva, da je beseda izpeljana iz praslovanščine in pomeni strm svet ali ozek prehod. Tuma navaja, da ledinsko ime pomeni »... zlahka hoden svet, složni svet v pobočju ali gozdu, da se obdela ... " (Tuma 1929, 28 v: Fabčič 2010, 44). Vendar, v kateremkoli pomenu razumemo to besedo, v vsakem odseva značilnosti terasirane pokrajine.

Eden od strukturnih tipov ledinskih imen so tudi imena, ki izražajo umestitev poimenovanega predmeta, bodisi s predložno besedno zvezo bodisi kot priponsko ime ali pa kot slovnično izpeljano ime s sklapljanjem samostalnika (Šekli 2006, 489). V obravnavanih katastrskih občinah so takšni primeri Pri Brezju na Ostrožnem Brdu, pod Ogrado (Pod Ograde), Podboršt, Pod Stran, Per Krisha, Pod Vra$z e, \mathrm{v}$ Dužci v Podgorju, Nad Praida v Kamnju in na Pušči v Šmartnem.

V treh obravnavanih katastrskih občinah (v Podgorju, Kamnjah in Šmartnem) se pojavlja ledinsko ime Brajde (Braida), tudi Braide, Stara Brajda in Brajda. Beseda brajda pomeni »... po ogrodju speljana

Slika 2: Ledinska imena $v$ delu katastrske občine Ostrožno Brdo.

str. 98 


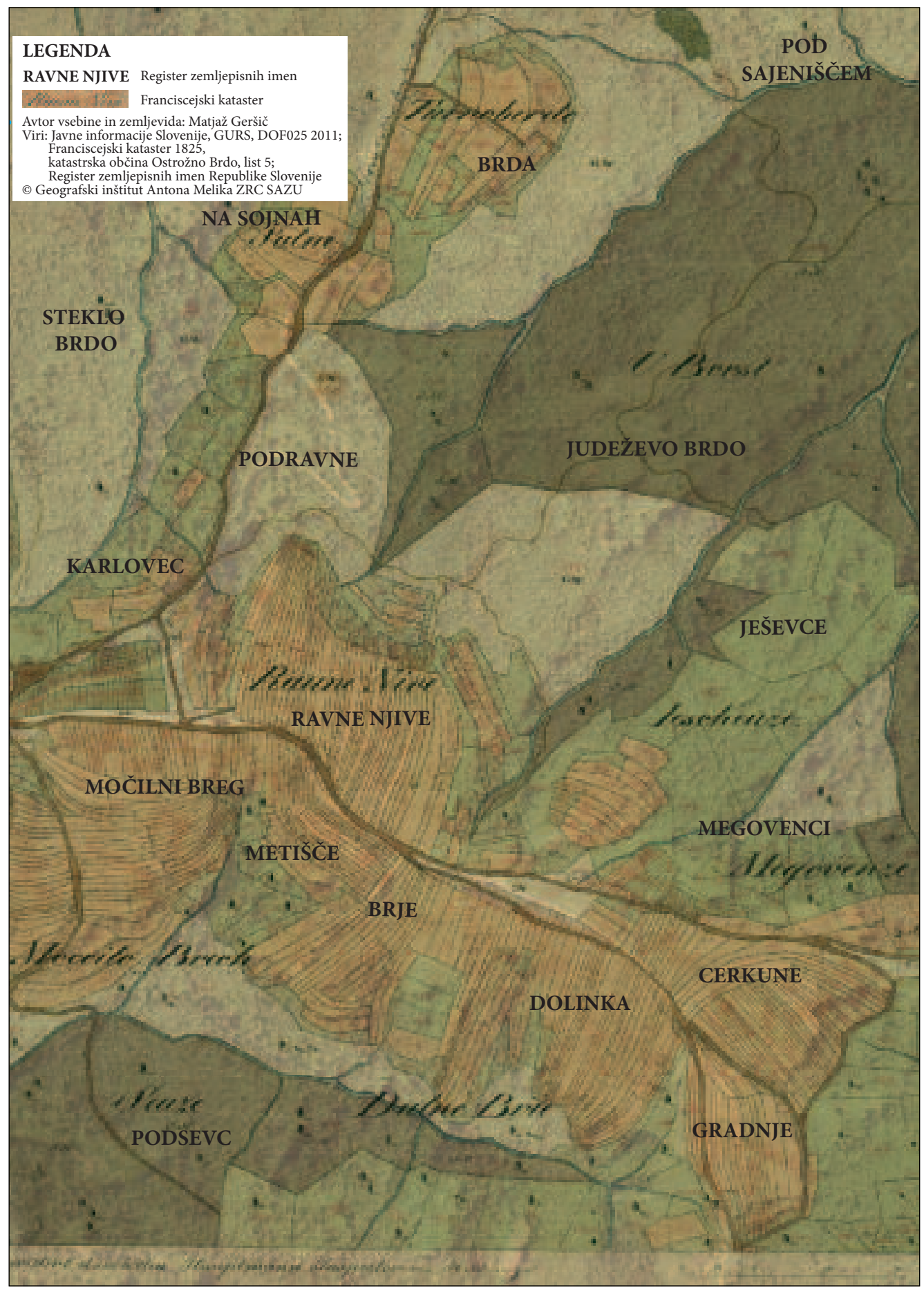


vinska trta, $v$ kraškem narečju tudi kos polja, nasajen s trtami ... «(Snoj 1997, 43). Iz imena lahko sklepamo na zemljiško rabo poimenovanega terasiranega območja, vendar moramo biti pri takšnih sklepih pazljivi, saj se na primeru Šmartna ledinski imeni pojavljata na gozdnatem površju. Mogoče je, da je bilo to nekoč terasirano in zasajeno $\mathrm{z}$ vinsko trto, razlog za takšno poimenovanje pa lahko tiči tudi v etimologiji besede brajda. Beseda je namreč prevzeta iz beneškega italijanskega izraza braida ali furlanskega izraza bràide, ki označuje majhno posestvo, razvila pa se je iz srednjeveškega latinskega izraza braida, povzetega iz langobardskega braida v pomenu "posestvo«, tudi »širina« (Snoj 1997, 43). Snoj dodaja, da furlanska beseda bràide pomeni tudi zagrajeno zemljišče, na katerem gojijo trto (Snoj 2009, 73-74).

V Krkavčah se na južni strani katastrske občine za večje terasirano območje pojavlja ledinsko ime Ukovca, v obeh katastrih pa Ugrada, kar je verjetno sopomenka sodobnega izraza ograda. Beseda ograda pomeni "... zemljišče, obdano z ograjo iz zloženega kamenja, grmovja, zlasti na kraškem svetu..." (Slovar ... 1998). Kot ogrado pogosto razumemo tudi zemljišče, ki je ograjeno in kjer se pase živina (Fabčič 2010, 83), kar za terasirano območje ni posebej logično. Se pa takšno ledinsko ime pojavi tudi v Lipovški vasi, zaselku Lozic v Zgornji Vipavski dolini, kjer označuje »... njivo oziroma lep kos zemlje brez kamenja ... «(Fabčič 2010, 103). To nas napeljuje k razmišljanju, da tovrstno ime lahko označuje tudi kakovostno zemljišče, nastalo s čiščenjem kamenja, kar gotovo velja tudi za terasirana območja.

$\mathrm{Na}$ Ostrožnem Brdu se na območju, v franciscejskem katastru poimenovanem Doline, v REZI-ju pojavlja ime Pleši. Zagotovo izhaja iz beseda pleša, ki pomeni »... golo, neporaslo zemljišče ali mesto v goz$d u$...« (Snoj 1997, 454). Podobno meni jezikoslovec Majdič $(1994,108)$, Badjura $(1953,26)$ pa navaja, da se ledinsko ime Pleša uporablja za manjše uravnave in kot sopomenke navaja izraze kres, seča, raven, gradišče. Zanimivo je, da se ledinsko ime terasiranega območja Gradišče pojavlja v Krkavčah.

\section{Sklep}

Ugotovimo lahko, da večina ledinskih imen ne pripada zamejenim terasiranim območjem, ampak poimenujejo širše območje. Pri nekaterih imenih lahko spremljamo kontinuiteto od franciscejskega katastra prek reambule do Registra zemljepisnih imen, vendar takšni primeri niso pogosti. Sporočilna vrednost ledinskih imen terasiranih območij v obravnavanih katastrskih občinah je zelo bogata. Iz njih lahko sklepamo predvsem na precejšnjo kakovost obdelovalne zemlje, rabo tal, reliefno razgibanost, ponekod tudi na lastništvo. Tako na primer ledinsko ime Cerkune na Ostrožnem Brdu izhaja iz cerkvenega lastništva parcele.

\section{Viri in literatura}

Badjura, R. 1953: Ljudska geografija, terensko izrazoslovje. Ljubljana.

Cathcart, T., Klein, D. M. 2008: Ste že slišali tistega o Platonu. Ljubljana.

Čop, D. 1983: Imenoslovje zgornjesavskih dolin. Doktorsko delo, Filozofska fakulteta Univerze v Ljubljani. Ljubljana.

Fabčič, T. 2010: Pripoved izročila talov. Lozice.

Franciscejski kataster za Goriško, katastrske občine Kamnje, Merče, Šmartno. Arhiv Republike Slovenije. Ljubljana, 1811-1869.

Franciscejski kataster za Istro, katastrski občini Krkavče in Podgorje. Archivio di Stato di Trieste/ Državni arhiv v Trstu. Trst, 1817-1825.

Franciscejski kataster za Kranjsko, katastrska občina Ostrožno Brdo. Arhiv Republike Slovenije. Ljubljana, 1823-1828.

Furlan, M., Gložančev, A., Šivic-Dular, A. 2001: Pravopisno ustrezen zapis zemljepisnih in stvarnih lastnih imen v Registru zemljepisnih imen in Registru prostorskih enot. Ljubljana. 
Geršič, M., Zorn, M. 2016: Odsev naravnih nesreč v zemljepisnih imenih - nekaj primerov iz Zahodnih Karavank in zahodnih Kamniško-Savinjskih Alp. Kronika 64-3.

Halbwachs, M. 2001: Kolektivni spomin. Ljubljana.

Ilešič, S. 1950: Sistemi poljske razdelitve na Slovenskem. Ljubljana.

Jarc, V. 2004: Starodavne poti pod Karavankami. Žirovnica.

Javne informacije Slovenije, DOF025. Geodetska uprava Republike Slovenije. Ljubljana, 2011.

Kadmon, N. 2000: Toponomy, the Lore, Laws, and Language of Geographical Names. New York.

Kadmon, N., Radovan, D., Majdič, V. 1995: Slovar toponimske terminologije. Ljubljana.

Kladnik, D. 1999: Leksikon geografije podeželja. Ljubljana.

Kladnik, D., Lovrenčak, F., Orožen Adamič, M. (ur.) 2005: Geografski terminološki slovar. Ljubljana.

Klinar, K., Geršič, M. 2014: Traditional house names as part of cultural heritage. Acta geographica Slovenica 54-2. DOI: http://dx.doi.org/10.3986/AGS54409

Klinar, K., Škofic, J., Šekli, M., Piko-Rustia, M. 2012: Metode zbiranja hišnih in ledinskih imen: Projekt FLU-LED v okviru Operativnega programa Slovenija-Avstrija 2007-2013. Jesenice, Celovec.

Kunaver, J. 1988: Zemljepisna imena v visokogorskem svetu in njihova uporaba na primeru Rombona in Goričice. Pokrajina in ljudje na Bovškem. Ljubljana.

Majdič, V. 1994: Pomenski izvor slovenskih krajevnih imen. Geografski vestnik 66.

Medmrežje 1: http://sl.wikipedia.org/wiki/Franciscejski_kataster (6.2.2014).

Penko Seidl, N. 2011: Ledinska imena v prostoru in času. Annales, Series historia et sociologia 21-2.

Penko, N. 2013: Kaj nam pove ledinsko ime? Medmrežje: http://www.ilbis.com/spark/st16cl6.htm (14.02.2013).

Peršolja, B. 2002: Zgoščeni imenik zemljepisnih imen. Dela 18.

Peršolja, B. 2003: Pot zemljepisnega imena od nastanka do uporabe. Geografski vestnik 75-2.

Piko-Rustia, M. 2010: Slovenska ledinska in hišna imena "po Unesco«. Novice: slovenski tednik za Koroško 24. Pogorelčnik, E. 1999: Zemljepisna imena - od zajema do standardizacije. Geodetski vestnik 43-2.

Reambulančni kataster za Goriško, katastrska občina Šmartno. Arhiv Republike Slovenije. Ljubljana, 1869.

Reambulančni kataster za Istro, katastrska občina Krkavče. Archivio di Stato di Trieste/Državni arhiv v Trstu. Trst, 1869.

Register zemljepisnih imen - REZI 5/10. Geodetska uprava Republike Slovenije. Ljubljana, 2013.

Relph, E. 1976: Place and Placelessness. London.

Ribnikar, P. 1982: Zemljiški kataster kot vir za zgodovino. Zgodovinski časopis 26-4.

Silič, V. 2012: Ledinska imena - naša bogata kulturna dediščina. Razgledi Muzejskega društva Bled. Bled. Slovar slovenskega knjižnega jezika. Ljubljana, 1998.

Snoj, M. 1997: Slovenski etimološki slovar. Ljubljana.

Snoj, M. 2009: Slovenski etimološki slovar. Ljubljana.

Šekli, M. 2006: Strukturni tipi ledinskih imen v kraju Livek in njegovi okolici. Jezikovna predanost, akademiku dr. Jožetu Toporišiču ob 80-letnici. Ljubljana, Maribor.

Titl, J. 2000: Toponimi Koprskega primorja in njegovega zaledja. Koper.

Titl, J. 2006: Kraški toponimi. Koper.

Tuma, H. 1929: Imenoslovje Julijskih Alp. Ljubljana.

\section{Summary: Field names in agricultural terraces}

(translated by Tina Potočnik Rodríguez)

Field names, defined as names of small unpopulated areas, identify the key features and characteristics of rural land. The borders between individual fields generally follow natural dividing lines, such as foothills, peaks and ridges, and riverbeds. Most fields were named by the locals, but some were also named by surveyors taking the measurements for individual cadastral registers. Other field names are 
simply general geographical terms adapted to certain geographical peculiarities. In these cases, the spelling signals a proper name. Due to modern processes of countryside transformation, the land categories of individual fields are no longer uniform, as was typical for fields in the past. Fields have thus lost their original meanings, although they are still perceived as a whole in the locals' consciousness, even though nowadays different types of land use can be found in the same field. Other field names have remained unchanged to this day, although they no longer relate to the original features after which they were named.

This article focuses on the field names of selected agricultural terraces in south-west Slovenia in order to determine whether the field names give an indication of any of the agricultural terraces' individual features.

The main sources of field names were data sources, namely two historical cadasters and 1:5,000 scale maps from the Republic of Slovenia Records of Geographical Names. By comparing archival and modern sources, it is possible to determine which names were lost, which appeared at a later point in time, etc. Unfortunately, historical cadasters lack a coordinate system, making it difficult to compare the location of individual names with today's situation. For this purpose, geographical information systems are used, as different cartographic layers of historical cadasters can be overlapped and then georeferenced in order to determine the locations of individual names on modern maps.

In the course of time, field names can lose their original material meaning, or become less transparent in terms of word formation. If they do not, they convey information on the condition and use of the region at the time of their creation having accompanied it in its transformation from an originally natural region to a modern cultivated region.

The selected cadastral municipalities from which the focus field names come from are very different from each other. In terms of onomastic research, a difference in the availability of sources and their inconsistency can be pointed out.

The cadastral survey under Emperor Francis I is available for all cadastral municipalities that were the subject of the research. However, in the Šmartno municipality, the number of field names is extremely low. The survey mostly contains former place names, which are nowadays mostly marked as field names. There is an improved version of the cadaster available for the settlements of Krkavče and Šmartno, although no field names can be found in the case of Šmartno. For other cadastral municipalities, no improved versions exist, as they were either never created, or have been lost or destroyed. For this reason, field names can be analysed only on the basis of the cadastral survey under Emperor Francis I as a historical source and the Records of Geographical names as a modern source of field names.

Defining fields as complete land units with the same economic value, as according to Jarc (2004), it can be established that agricultural terraces have an extremely low rate of field names covering exclusively the terraces within their borders. Field names mostly cover wider areas whose parts have been changed into terraces, or several field names may be used for one terraced area.

It has been established that most field names cross the boundaries of a single terraced area, as they denote wider areas. Some names show continuity between the cadaster under the Emperor Francis I, its improved version and the Records of Geographical Names, although such cases are rare. In the focus cadastral municipalities, the selected field names of terraced areas convey important information. In particular, they relate to a high quality of cultivated land, land use, terrain heterogeneity and, to a certain extent, ownership. For example, the field name Cerkune in Ostrožno Brdo indicates that the parcel was owned by the Church. 
